Canadian Journal of Family and Youth, 2(1), 2009, pp 25-51

ISSN 1718-9748@University of Alberta

http://ejournals.library.ualberta.ca/index/php/cjfy

\title{
Examining How the Mental Health Needs of Children Who Have Experienced Maltreatment are Addressed within Ontario Children's Aid Societies
}

\author{
Jennifer Czincz and Elisa Romano
}

\begin{abstract}
American data suggest that there is often a lack of mental health service provision to children in the child welfare system that have experienced maltreatment and are exhibiting psychological difficulties. These data are concerning given that the existing literature unanimously concludes that children who have experienced maltreatment present with significantly higher rates of mental health difficulties than general samples of children in the community. Given that little Canadian research has been conducted in this area, this study examined the need identification and referral process made to mental health services by Ontario Children's Aid Societies (CAS) for children who have experienced maltreatment. Findings indicate a high prevalence of mental health difficulties in this population and a limited standardized approach to the identification and assessment of these issues. It was found that the majority of children who do receive referrals to mental health services are referred to community-based psychologists. Findings regarding the tracking of community referrals and interagency collaboration were encouraging as compared to American data.
\end{abstract}

\section{Introduction}

Based on the existing literature, it is evident that child maltreatment is prevalent in society and often has significant deleterious effects on the victim. The Canadian Incidence Study of Reported Child Abuse and Neglect (Trocmé et al., 2005) conducted in 2003 reported an incidence rate of 18.7 cases of substantiated maltreatment per 1,000 Canadian children. This represented a $125 \%$ increase in cases of substantiated maltreatment in Canada from data

\footnotetext{
Jennifer Czincz is a doctoral student in Clinical Psychology at the University of Ottawa. Her work involves an examination of the availability and quality of mental health services in Ontario for children who have been sexually abused. She has co-authored two treatment manuals for children who have been sexually abused and their nonoffending caregivers and facilitated a research capacity building workshop with psychologists in South East Asia. Elisa Romano is an Associate Professor of Psychology at the University of Ottawa. Her research interests include child maltreatment, child development and psychopathology, and treatment evaluation. Her publications have appeared in journals such as the Journal of Family Violence and Pediatrics. Correspondence on this article should be directed to Jennifer Czincz at jczin102@uottawa.ca.
} 
collected five years earlier. It is also likely that these statistics are a gross underrepresentation of the true extent to which children experience maltreatment for a number of reasons. First, substantiating cases of maltreatment can be particularly challenging as confirming evidence of the incidence is not always available, especially when some time has passed since the occurrence. Second, a significant proportion of child maltreatment cases are never reported to either child welfare agencies or police services (MacMillan \& Munn, 2001; Statistics Canada, 2004). Third, children's view of behaviour as being abusive or their perception of the severity of the maltreatment has been found to differ greatly from observer reports, for example, child welfare workers (Bolger \& Patterson, 2001; Gable, 1998). Finally, reports of childhood maltreatment have also been shown to have poor reliability and stability over time (Fergusson, Horwood, \& Woodward, 2000).

While this is an area that still requires more research, the existing literature unanimously concludes that children who have experienced maltreatment present with significantly higher rates of mental health difficulties than general samples of children in the community (Burns et al., 2004; Staudt, 2003). The literature presents estimates ranging from $45 \%$ to $80 \%$ for the percentage of children who have experienced maltreatment and exhibit clinically significant psychological difficulties that require mental health interventions (Burns et al., 2004; Farmer, Burns, Chapman, Phillips, \& Costello, 2001; Staudt, 2003; Taussig, 2002).

In terms of specific symptomatology, depression, anxiety, and behavioural difficulties tend to be most prevalent among children with a history of maltreatment (Trocmé et al., 2001). However, many other symptoms have been noted, including developmental delays, self-harming behaviours, and psychiatric disorders (Trocmé et al., 2001). Several factors that have been shown to account for differentiation in presenting problems among children who have experienced 
Mental Health Needs of Children

maltreatment are the type of maltreatment experienced (physical abuse; sexual abuse; neglect; emotional maltreatment), age of onset, duration of maltreatment, gender of the child, perpetrator characteristics, and social support following disclosure (Burns et al., 2004; Staudt, 2003, Tremblay, Hebert, \& Piche, 1999).

\section{Mental Health Service and Maltreated Children}

As child maltreatment is one of the most preventable contributors to both child and adult mental illness, early assessment and intervention of mental health difficulties in this population would appear to be a top priority. The child welfare system represents a critical means through which to identify and intervene in the mental health difficulties of children who have experienced maltreatment. These are the required reporting agencies for child maltreatment and sometimes the sole point of contact with a social service resource for youth. The present study comes at a critical point in the evolution of the child welfare system in Ontario, as there has been a recent shift from a focus primarily on child safety and protection toward a more comprehensive model of child wellbeing. While the recent development of the Child Protection Standards in Ontario provides guidance and standardized tools to screen for mental health difficulties, there has not yet been systematic research conducted regarding the extent of implementation and effects of these standards.

While little Canadian research has been conducted in this area, there is strong evidence in the United States of inadequate mental health service provision to children who have a history of maltreatment and are in contract with the child welfare system (Burns et al., 2004, Kolko et al., 2003; Staudt, 2003). The National Survey of Child and Adolescent Well-being (NSCAW) provided the first national estimates of mental health need and service use in the U.S. child welfare population (Burns et al., 2004). Results demonstrated that, while approximately half of 
children involved with the child welfare system exhibited clinically significant psychological difficulties as assessed by the Child Behavior Checklist (CBCL), only $11.7 \%$ of these children had received any mental health services within the past 12 months (Burns et al., 2004). The authors speculate that the following factors may contribute to the observed gap between service need and use: (1) inadequate resources; (2) overworked child welfare employees with limited time to properly assess need for services; (3) failure to provide child welfare staff with sufficient training in the identification of mental health issues.

Geographic location (i.e., urban versus rural) has also been shown to influence both the availability and quality of mental health services for this population. While the prevalence of both mental health difficulties and child maltreatment have been shown to be similar or greater in rural versus urban areas, a larger gap between need and mental health service use has been noted among rural residents (Bjorklund \& Pippard, 1999; Hanrahan \& Hartley, 2008; Lin, Goering, Offord, Campbell, \& Boyle, 1996; Paul, Gray, Elhai, Massad, \& Stamm, 2006; RyanNicholls \& Haggarty, 2007). Specific barriers to mental health service provision in rural areas include a shortage of service providers, a lack of training opportunities in clinical interventions for mental health service providers, lack of specialization opportunities for clinicians, and difficulties with accessibility to services. Additional barriers are stigma of mental health and difficulties with client confidentiality given the small size of the community (Bjorklund \& Pippard, 1999; Ryan-Nicholls \& Haggarty, 2007).

The current study sought to provide an overview of how mental health needs are identified and addressed in children involved with Ontario Children's Aid Societies CAS agencies. The research was supported by the Ontario Association of Children's Aid Societies (OACAS), which is the umbrella organization representing all CAS agencies in Ontario. 
Mental Health Needs of Children

Information was gathered from the directors of Ontario CAS agencies by way of a questionnaire that was structured around the factors identified as being most responsible for failures in mental health service delivery to the child welfare population (i.e., McLennan et al., 2003; Staudt, 2003). These factors include mental health need identification, service referrals and provision, resource allocation, and interagency communication between the child welfare sector and community services. It was predicted that findings would reflect U.S. data in the following ways: (1) there would be a high prevalence of mental health difficulties in this population; (2) there would be a limited structured approach to mental health need identification; (3) a limited proportion of children in need of mental health services would receive referrals for treatment; (4) there would be limited tracking of community referral outcomes by CAS agencies; (5) there would be limited interagency communication between the child welfare sector and community services; and (6) the prevalence of mental health difficulties in this population will be greater in rural versus urban areas and there will be a larger gap between need and use of mental health services among rural residents.

\section{Method}

This study contacted the directors of services at each of the 53 CAS agencies in Ontario by email and telephone. The names of these individuals were obtained from the OACAS. An overall response rate of $77.4 \%(\mathrm{~N}=41)$ was obtained for this study. The questionnaire, which included a number of open- and close-ended questions, focused on factors identified in the literature as contributing to mental health service utilization by youth involved with the child welfare system: identification and assessment of mental health needs; the process of referring clients in need to mental health treatment services; resource allocation; and interagency 
collaboration between the child welfare sector and community mental health services. The questionnaire used in this study was developed based on the existing literature and on items from the About You and Where You Work questionnaire (Kolko, Cohen, Mannarino, and Knudsen, 2008) that surveyed workplace settings, treatment practices, and attitudes of clinicians who work with children who have experienced maltreatment. In addition, the Director of Psychological Services at one of the Ontario CAS agencies was consulted to ensure that the questions and terminology used were appropriate (A copy of the questionnaire is presented in Appendix A).

Participants were contacted a total of five times by email and/or telephone. These contacts included a pre-notification email and voicemail, an email with the questionnaire attachment, and three subsequent follow-up contacts (two by email and one by telephone). The questionnaire was sent as an email attachment and participants were asked to complete the questionnaire and return it either in the body of the email or as an attachment. Data were gathered between October and December 2008. In terms of the length of time it took respondents to complete and return the survey, $48.8 \%(n=20)$ of the surveys were returned following the initial email, $24.4 \%(\mathrm{n}=10)$ were returned following the first follow-up email, $24.4 \%(\mathrm{n}=10)$ were returned following the second follow-up email/voicemail, and $2.4 \%(\mathrm{n}=1)$ were returned following the final email notice. The majority of surveys were returned by email $(95.2 \% ; \mathrm{n}=$ $39)$, while one survey was returned by fax $(2.4 \% ; n=1)$ and one by mail $(2.4 \% ; n=1)$.

The majority of questions had dichotomous response options, and responses to these questions were assessed quantitatively through descriptive analyses. In addition, comparative analyses were conducted based on the location of agencies (rural versus urban). Definitions of rural and urban were based on Statistics Canada's (2006) three-tier definition of rural and urban regions. Large urban areas were defined as one or more adjacent municipalities centered on an 
Mental Health Needs of Children

urban core having a population of at least 50,000. Small urban areas were defined as any urban area that has a minimum population of 1,000 persons and population density of at least 400 persons per square kilometre. This category also included areas that are part of a census agglomeration, as defined by Statistics Canada (2006). Rural areas were defined as all areas that do not fall into the categories of either large or small urban areas. Three of the questions (numbers 2, 6, and 7) were qualitative in nature and were assessed through a qualitative analysis of themes conducted by two independent assessors in order to determine the broader categories of responses. Each assessor reviewed responses independently and categorized them according to overriding themes. A high level of agreement was found with the assessors' thematic coding of all three questions. Percent agreement was $89 \%$ for question $2,92 \%$ for question 6 , and $90 \%$ for question 7. Following a review of the identified themes for each question, the assessors came to a consensus regarding the thematic coding of each open-ended question.

\section{Results}

Based on the responses of CAS directors of psychological services, the mean number of mental health professionals employed at Ontario CAS agencies was $136.26(\mathrm{SD}=105)$ with a range from 10 to 478 . The specific types of professionals employed at the agencies were, in decreasing order, social workers $(M=87.92, S D=91.2)$, child and youth workers $(M=20.64$, $\mathrm{SD}=29.4)$, psychologists $(\mathrm{M}=0.26, \mathrm{SD}=0.6)$, and psychiatrists $(\mathrm{M}=0.1, \mathrm{SD}=0.5) . \mathrm{CAS}$ directors of services also noted that "other staff” $(\mathrm{M}=27.31, \mathrm{SD}=43)$ were employed, which typically included counsellors, administrative staff, and management. As would be expected, the greatest number of mental health professionals in all categories were employed at urban 
agencies, while fewer were employed at agencies located in small urban settings, and even fewer in rural agencies.

Based on responses to the question "what is the process used to identify the mental health needs of children and adolescents served by your agency?", four themes were identified: (1) unstructured interview or observation of the child or adolescent; (2) interviews with caregivers or teachers; (3) implementation of structured screening tools; and (4) lack of any standardized assessment process (for a full list of responses, including a breakdown of responses by geographic location, see Appendix B).

Based on responses from CAS directors of psychological services, the most common strategy for identifying the mental health needs of youth involved in child welfare was an unstructured interview or observation of the youth followed by the use of some form of structured screening tool. Note that these were not mutually exclusive categories so it was possible for an agency to indicate using more than one strategy (e.g., structured screening tools and interview data from caregivers). Of the $55 \%(n=22)$ of respondents who did endorse using some form of structured screening tool in the identification of mental health needs of youth in child welfare, only six directors (15\%) endorsed using the specific tools recommended by the Ministry of Children and Youth Services that assess child mental health (i.e., Ontario Family and Child Strength and Needs Assessment, Strengths and Difficulties Questionnaire). Having said this, it appears that a number of additional tools are being used to assess mental health difficulties, including the Brief Child and Family Phone Interview; the Child and Adolescent Functional Assessment Scale; and the Ontario Looking After Children Assessment and Action Record. 
Mental Health Needs of Children

Given that mental health assessment might vary by the type of maltreatment experienced by the youth, we examined this possibility. However, the majority of CAS directors of services $(81 \% ; n=30)$ reported that the assessment process did not vary by maltreatment type. The respondents that did describe the process as varying by type of maltreatment reported that if a child or adolescent had experienced a specific maltreatment type, s/he would typically be referred to a community agency or program that dealt explicitly in terms of assessment and/or treatment with that particular type of maltreatment. In terms of the geographic location of respondents who endorsed the process as varying by type of maltreatment, $57.1 \%(\mathrm{n}=4)$ were from an urban setting, $28.6 \%(\mathrm{n}=2)$ were from a small urban setting, and $14.3 \%(\mathrm{n}=1)$ were from a rural setting.

\section{Referrals to Mental Health Services}

CAS directors of services were asked about the approximate percentage of youth being served by their agency that required a referral to therapeutic services. The responses provided to this question varied greatly, with a mean of $57.9 \%(\mathrm{SD}=22.2)$, a minimum response of $15 \%$ and a maximum response of $95 \%$. In terms of varying as a function of geographic location, the mean response for urban agencies was $52.9 \%$, for agencies located in small urban areas the mean was $59 \%$, and the mean was $67.5 \%$ for agencies located in a rural setting.

In response to the question "are therapeutic services available at your agency for children and adolescents who have mental health needs?", approximately half of the CAS directors of services $(48.8 \% ; n=20)$ reported that there were mental health services offered within their CAS agency, including assessment and intervention (individual and/or group counselling, play therapy, family therapy). In addition, half $(\mathrm{M}=50.9 ; \mathrm{SD}=35.8)$ of the referrals for mental health services are handled by the agency itself. It should be noted, however, that there was wide variability in the 
percentage of mental health referrals handled within the agency itself (5\% to $100 \%)$. In terms of the geographic location of CAS agencies offering in-house mental health services, $50 \%(\mathrm{n}=10)$ were from a large urban area, 35\% $(\mathrm{n}=7)$ were from a small urban area, and $15 \%(\mathrm{n}=3)$ were from a rural area. The mental health professionals reported to be providing services within the CAS agencies were primarily social workers $(80 \% ; n=16)$, followed by child and youth workers $(55 \% ; \mathrm{n}=11)$, psychologists $(55 \% ; \mathrm{n}=11)$, psychiatrists $(40 \% ; \mathrm{n}=8)$, and other therapists or counsellors $(40 \% ; \mathrm{n}=8)$.

In addition to within-agency services, almost all CAS directors of services $(95.1 \%$; $\mathrm{n}=$ 39) reported that referrals are made to community-based professionals and agencies to address the mental health needs of youth being served by their agency. The mental health providers in the community to which most of the referrals were reported to be made were psychologists $(79.5 \% ; n=31)$, followed by social workers $(61.5 \% ; n=24)$, mental health centers or hospitalbased services $(59 \% ; \mathrm{n}=23)$, psychiatrists $(56.4 \% ; \mathrm{n}=22)$, child and youth workers $(25.6 \% ; \mathrm{n}=$ $10)$, and other therapists or counsellors $(15.4 \% ; n=6)$. The approximate percentage of overall referrals made to any community-based mental health service in a given year ranged from $5 \%$ to $100 \%(\mathrm{M}=78.7 ; \mathrm{SD}=31.5)$.

For community-based referrals, $(53.8 \% ; \mathrm{n}=21)$ of participants reported that there was a tracking process in place to monitor the outcome of these referrals. The most common tracking process was plan of care meetings, followed by tracking based on expenditures for community mental health services. For those respondents who endorsed having a tracking process in place, $61.9 \%(n=13)$ were from large urban settings, $23.8 \%(n=5)$ were from small urban settings, and $14.3 \%(n=3)$ were from rural settings. 
Mental Health Needs of Children

\section{Resource Allocation}

In terms of how fees are typically handled for the mental health services provided within CAS agencies, $80 \%(n=16)$ of respondents reported that the agency covers all fees and $20 \%(n$ = 4) stated that the in-house services are government-funded. For the payment of fees for community-based mental health services to which the youth are referred, half of the CAS directors of services $(51.3 \% ; n=20)$ reported that the agency covers these fees, while $41 \%(n=$ 16) stated that most referrals are made to government-funded services, and $7.7 \%(n=3)$ reported that the client is responsible for fee payment.

\section{Partnerships or Collaborative Projects in the Community}

The majority of CAS directors of services $(90.2 \% ; n=37)$ reported that their agencies had partnerships or collaborative projects with mental health service providers in the community. These partnerships were reported in $45.9 \%(n=17)$ of CAS agencies from large urban settings, 40.6\% $(n=15)$ from small urban settings, and $13.5 \%(n=5)$ from rural settings. CAS directors of services who indicated having community partnerships were asked to describe the nature of such partnerships. Based on their responses, four themes were identified: (1) the presence of collaborative projects or joint programming with community mental health service providers; (2) the presence of a contract or agreement with community mental health service providers to serve youth involved with CAS; (3) funding partnerships between CAS and community service providers for the provision of mental health services for youth involved with CAS; and (4) the collaborative development of shared protocols with community service providers for mental health service provision to youth involved with CAS (a full list of responses by theme is presented in Appendix C). 


\section{Modifications Suggested to the Process of Identification and Service Provision}

CAS directors of services were asked to answer the question: what (if any) changes would you make in the process of identifying mental health needs and providing therapeutic services or referrals for children and adolescents being served by your agency? Based on their responses, six themes were identified: (1) the need for a greater number of community-based child and adolescent mental health services; (2) the need for improved efficiency in the identification of mental health needs of youth involved with CAS; (3) the need for more mental health services within CAS agencies; (4) the need for more funding directed to youth mental health services; (5) the need for increased accountability and tracking of outcomes; and (6) no changes necessary. A full list of responses is presented in Appendix D.

\section{Discussion}

This is the first study to our knowledge that has examined mental health need identification and service referral for children involved with the Canadian child welfare system. The director of services from 41 (of 53) Ontario CAS agencies reported on the identification and assessment of mental health needs in child welfare youth, the process of referring youth in need to mental health treatment services, resource allocation, and interagency collaboration between the child welfare sector and community mental health services. Many of the results were consistent with U.S. data, indicating that there is a high need for mental health services in this population but often a limited systematic approach to the identification and treatment of these difficulties. 
Mental Health Needs of Children

Our first hypothesis regarding the high prevalence of mental health difficulties in children involved with the child welfare system was supported. While our results were variable, they indicated that about 6 in 10 CAS directors of services believed youth in child welfare to have mental health concerns that are serious enough to warrant intervention. This result reflects previous findings regarding the high prevalence of mental health difficulties in this population (Burns et al., 2004; Staudt, 2003). Data also supported our second hypothesis, which stated that there would be a limited systematic and structured approach to the identification of mental health needs for children involved with child welfare. While just over half of the agencies appeared to be using some form of structured screening tool to identify mental health needs among youth, only $15 \%$ of these agencies were making use of the tools recommended by the Ontario Child Protection Standards for the assessment of child mental health. The fact that mental health difficulties are not assessed in a standardized manner across agencies likely means that many children in need of services are not identified and referred for treatment. While this matter should be investigated further by future studies, these findings give some preliminary support to our third hypothesis that a limited proportion of children in need of mental health services will receive referrals for treatment.

Turning to the service referral process, findings indicated that less than half of Ontario CAS agencies are currently offering any type of mental health service to youth. This is somewhat surprising given the shift that has occurred over the past decade in child welfare from an exclusive focus on child protection issues toward a more holistic approach to child wellbeing (Leslie, 2007). In the agencies that do offer services, they are provided primarily by social workers, followed by psychologists and child/youth workers. Almost all agencies make referrals 
to community-based mental health services, primarily psychologists, followed by social workers, and mental health centers or hospital-based services.

Contrary to our fourth and fifth hypotheses and previous U.S. findings (Darlington, Feeney, \& Rixon, 2004; Darlington, Feeney, \& Rixon, 2005), results from our study indicated that community referral outcomes were tracked by over half of the CAS agencies and also that interagency collaboration between the child welfare sector and community mental health services was in place in $90 \%$ of agencies. While these results are difficult to interpret given the lack of comparative data available, it has been noted that the strongest contributing factors to successful collaboration between child welfare agencies and community services are support of these partnerships at the individual, organizational, and policy level (Darlington et al., 2004).

Findings related to the geographic location of agencies were consistent with previous literature indicating that, while the prevalence of mental health difficulties is similar or greater in rural versus urban areas, a larger gap between need and mental health service use exists among rural residents (Bjorklund \& Pippard, 1999; Hanrahan \& Hartley, 2008; Lin et al., 1996; Paul et al., 2006; Ryan-Nicholls \& Haggarty, 2007). Agencies located in rural settings reported a greater percentage of youth who have mental health needs requiring a referral to mental health services. However, these agencies reported employing fewer mental health professionals, having a less standardized approach to mental health need identification, offering fewer in-house mental health services, and having fewer partnerships or collaborations with community mental health services. It is important to note that the response rate from agencies located in a rural setting was low, which may have influenced the results. Nonetheless, these findings indicate that there appears to be a greater need for mental health services among rural youth involved with child 
Mental Health Needs of Children

welfare and less availability of these resources for this population as compared to services offered in urban areas.

In sum, findings from the present study indicate that many youth involved with the Ontario child welfare system who are in need of mental health services may not be identified and/or referred for treatment services. The most likely reason for limited service provision appears to be a limited standardized and systematic approach to the identification and assessment of mental health issues in this population. It may be that this is a result of organizational factors that have been identified in the literature as potentially contributing to difficulties in identifying mental health needs of children involved with child welfare. Examples of such factors include: (1) child welfare agencies putting the majority of their resources into investigative and protection issues, leaving few resources for mental health need identification and service delivery; (2) funding shortages (leading to service discontinuity and lack of services); (3) high caseloads; (4) mandated worker deadlines; (5) reduced qualifications of staff; and (5) high staff turnover rates (Faver, Crawford, \& Combs-Orme, 1999). Addressing the challenges in identifying and assessing mental health issues in this population is a critical issue not only given the problems of service provision to children in need, but also the limited ability to gather province-wide data related to these children in order to address service gaps and influence policy.

In terms of the limitations of this study, since the director of service for each agency completed the questionnaire, it is possible that different responses would have been gathered if other members of the agency were surveyed. However, the director of service was identified as being the most knowledgeable and most able to respond to the questionnaire by both the researchers and the OACAS. The fact that participants were asked to provide approximate responses for some questions may also have influenced the accuracy of findings. Another 
possible limitation of the study is that it examined the identification and assessment of mental health difficulties for youth who have experienced maltreatment in general and did not differentiate among maltreatment type (e.g., physical abuse, sexual abuse, neglect). However, this decision was based on consultation with a CAS director of service who indicated that agencies tend not to have different assessment and referral strategies as a function of maltreatment type. Findings also confirmed this statement, as the majority of CAS directors of services $(81 \%)$ did not report differentiation in the assessment or referral process based on type of maltreatment agency. Lastly, as 12 of the 53 potential respondents did not participate in the survey, the findings do not represent a complete and comprehensive picture of the mental health need identification and service referral process for all Ontario CAS agencies. 


\section{Appendix A}

Email Questionnaire

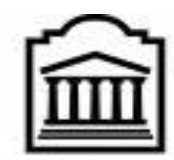

\section{uOttawa}

L'Universitế canadienne Canada's university

\section{The Identification and Treatment of Mental Health Needs Among Children and Adolescents Who Have Experienced Maltreatment}

1) Please provide the approximate number of mental health professionals currently employed at your agency:

_ Social Workers

Child and Youth Workers

Psychologists
Psychiatrists

Other (please specify :

2) What is the process used to identify the mental health needs of children and adolescents served by your agency?

(Please include any policies or assessment tool in place related to this process)

-Does the process vary based on type of maltreatment experienced? If so, how?

3) In a typical one-year period, approximately what percentage of children and adolescents who have experienced maltreatment and who are being served by your agency have mental health needs that require a referral to therapeutic services?

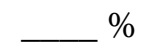

4) Are therapeutic services available at your agency for children and adolescents who have mental health needs?
_ Yes
No (Skip to next question)

If yes: What types of services are available?

Which professionals would typically provide these services?

In a typical one-year period, approximately what percentage of overall referrals made to therapeutic services is provided by your agency for children and adolescents who have mental health needs?

\section{$\%$}


How are fees typically handled for these services?

5) Are referrals to community-based therapeutic services made to address the mental health needs of children and adolescents being served by your agency?

_ Yes _ _ No (Skip to next question)

If yes: To which professionals are most of these referrals made (e.g., psychologists, social workers, psychiatrists, child and youth workers)?

Which professionals at your agency typically make these referrals?

In a typical one-year period, approximately what percentage of overall referrals made to therapeutic services is made to community-based services to address the mental health needs of children and adolescents being served by your agency?

$\%$

How are fees typically handled for these services?

What is the process (if any) for tracking whether children and adolescents receive services in the community for their mental health needs?

6) Does your agency have any partnerships or collaborative projects with mental health service providers in the community?

If yes: Please briefly describe the nature of these partnerships or projects

7) What (if any) changes would you make in the process of identifying mental health needs and providing therapeutic services or referrals for children and adolescents being served by your agency? 


\section{Appendix B}

Complete List of Responses to Question 2:

What is the process used to identify the mental health needs of children and adolescents served by your agency? (Please include any policies or assessment tool in place related to this process)

\begin{tabular}{|c|c|c|}
\hline Assessment Process & $\begin{array}{l}\text { Number of } \\
\text { Endorsing Agencies }\end{array}$ & Geographic Location \\
\hline No specified assessment process & $1(2.5 \%)$ & 1 Large Urban \\
\hline $\begin{array}{l}\text { Unstructured interview/observation by } \\
\text { CAS worker }\end{array}$ & $26(65 \%)$ & $\begin{array}{l}15 \text { Large Urban } \\
9 \text { Small Urban } \\
2 \text { Rural }\end{array}$ \\
\hline $\begin{array}{l}\text { Interview with families and collaterals (i.e., } \\
\text { teachers, etc.) }\end{array}$ & $8(20 \%)$ & $\begin{array}{l}5 \text { Large Urban } \\
3 \text { Small Urban }\end{array}$ \\
\hline Structured Screening Tools: & & \\
\hline $\begin{array}{l}\text {-Did not specify all the specific tools used } \\
\text { (but mentioned use of additional } \\
\text { assessment tools) }\end{array}$ & $5(12.5 \%)$ & $\begin{array}{l}2 \text { Large Urban } \\
2 \text { Small Urban } \\
1 \text { Rural }\end{array}$ \\
\hline -Battelle Developmental Inventory & $1(2.5 \%)$ & 1 Large Urban \\
\hline $\begin{array}{l}\text {-Brief Child and Family Phone Interview } \\
\text { (BCFPI) }\end{array}$ & $6(15 \%)$ & $\begin{array}{l}2 \text { Small Urban } \\
4 \text { Rural }\end{array}$ \\
\hline $\begin{array}{l}\text {-Child and Adolescent Functional } \\
\text { Assessment Scale (CAFAS) }\end{array}$ & $7(17.5 \%)$ & $\begin{array}{l}3 \text { Small Urban } \\
4 \text { Rural }\end{array}$ \\
\hline -Child 30 Day Assessment Questionnaire & $1(2.5 \%)$ & 1 Large Urban \\
\hline -Child Emotional Wellbeing Screen & $2(5 \%)$ & $\begin{array}{l}1 \text { Large Urban } \\
1 \text { Small Urban }\end{array}$ \\
\hline $\begin{array}{l}\text {-Child \& Family Strengths and Needs } \\
\text { Assessment }\end{array}$ & $3(7.5 \%)$ & $\begin{array}{l}2 \text { Large Urban } \\
1 \text { Small Urban }\end{array}$ \\
\hline $\begin{array}{l}\text {-Differential Response Protection } \\
\text { Recordings }\end{array}$ & $1(2.5 \%)$ & 1 Large Urban \\
\hline -Eligibility Spectrum & $2(5 \%)$ & $\begin{array}{l}1 \text { Large Urban } \\
1 \text { Rural }\end{array}$ \\
\hline
\end{tabular}


-Family Support Scale

-Mental Health Index 5

-Ontario Risk Assessment Tool

(prescribed by Ministry)

-Ontario Looking After Children

Assessment and Action Record (ONLAC)

-Nipissing District Developmental Screen (NDDS)

-Plan of Care

-Symptom-Specific Psychometric

Questionnaires (i.e., Conners, Depression Scale)

-Strengths and Difficulties Questionnaire
$1(2.5 \%)$

$1(2.5 \%)$

$4(10 \%)$

$7(17.5 \%)$

$2(5 \%)$

$7(17.5 \%)$

$2(5 \%)$

$2(5 \%)$
1 Large Urban

1 Small Urban

2 Large Urban

2 Small Urban

5 Large Urban

2 Small Urban

2 Large Urban

4 Large Urban

3 Small Urban

2 Rural

2 Small Urban 


\section{Appendix C}

Complete List of Responses to Question 6:

Does your agency have any partnerships or collaborative projects with mental health service providers in the community? If yes: Please briefly describe the nature of these partnerships or projects

Themes and Specific Responses Number of Geographic Location Endorsing Agencies

Theme 1: Collaborative projects or joint programming with community mental health service providers

Sample Responses:

-Family Connects Program (a program for adult and individual counseling supported with ministry funding)

-Women's Advocate Program (a women's advocate from local women's shelter attends home visits with a child protection worker where concern re domestic violence exist- supported with ministry funding) -Provision of evidence-based treatments collaboratively with community providers (i.e., Triple P program)

Theme 2: Contract or agreement with community mental health service providers to serve children or adolescents involved with CAS

Specific Responses:

-Contract/service agreement with psychologists and/or psychiatrists for mental health assessment and treatment services

Theme 3: Funding partnerships between CAS and community service providers

Specific Responses:

-CAS providing funds for mental health services in the community specifically for children involved with CAS

-Involvement of CAS agencies in committees/collaborative conferences
$31(75.61 \%)$

16 Large Urban 13 Small Urban 2 Rural
$11(26.83 \%) \quad 7$ Large Urban

3 Small Urban

1 Rural
$5(12.20 \%) \quad 3$ Large Urban

2 Small Urban 
regarding mental health service provision to CAS clients and/or funding in partnership with community service providers

Theme 4: Collaborative development of shared protocols with community service 2 Rural

providers for mental health service provision to children involved with CAS

Specific Responses:

- Collaborative development of shared protocols regarding mental health service provision to children involved with CAS with agencies such as OPP, school boards, community mental health agencies, hospitals, and community living agencies. 


\section{Appendix D}

Complete List of Responses to Question 7:

What (if any) changes would you make in the process of identifying mental health needs and providing therapeutic services or referrals for children and adolescents being served by your

$$
\text { agency? }
$$

Themes and Specific Responses

Number of

Geographic

Endorsing Agencies Location

Theme 1: Need for a greater number of child and adolescent mental health services and resources in the community

Specific Responses:

-There are not enough resources to meet the number and complexity of children's mental health needs in the community. -It would be most beneficial if waiting lists could be decreased for those children and youth who are being identified as most needy.

-Children's mental health services should be mandated when assessment/diagnosis indicates a need for treatment/intervention.

Theme 2: Need for improved efficiency in the identification of mental health needs of children and adolescents involved with CAS

Specific Responses:

-We have advocated having training and access to the same assessment tools that mental health providers use to screen for mental health needs and to assess outcomes. -We do not currently have any standardized screening mechanism or tools to assist frontline child protection staff in the identification of children with mental health needs. -Clearer process for identifying children with mental health concerns and better tracking of this across agency and not just with children in care.
4 Large Urban

3 Small Urban 
Theme 3: Need for more mental health

4 Large Urban services (both professionals and treatment 1 Rural services) within CAS agencies

Specific Responses:

-Our preference would be to establish an in house clinical team consisting of both a psychologist and a psychiatrist.

-I feel we should have a psychologist on staff.

-Mental health professional(s) assigned exclusively to child welfare services, as well as a crisis response team for child welfare clients.

Theme 4: Increased funding directed to mental health services for children and adolescents

\section{$3(9.09 \%) \quad 2$ Small Urban 1 Rural}

Specific Responses:

-Improved funding for children's mental health services that are evidence based and outcome oriented. Children's mental health is chronically underfunded in our area likely resulting in increased referrals to child protection.

-More funding to child mental health services so that children are able to be assessed within reasonable time lines.

Theme 5: Increased accountability and tracking of outcomes for children and adolescents involved with CAS who are referred for mental health services

Specific Responses:

- Better tracking of referrals; better follow up to determine if families engage with other service providers.

- There needs to be more accountability and coordination of services between the children's mental health programs and the child welfare system.

Theme 6: No changes necessary in the process of identification and service provision for mental health needs of children being served by CAS 
Mental Health Needs of Children

\section{References}

Bjorklund, R.W. \& J.L Pippard. 1999. "The Mental Health Consumer Movement: Implications for Rural Practice.” Community Mental Health Journal, Vol. 35, pp. 347-359.

Bolger, K.E. \& C.J. Patterson. 2001. "Pathways from Child Maltreatment to Internalizing Problems: Perceptions of Control as Mediators and Moderators." Development and Psychopathology, Vol. 13, pp. 913-940.

Burns, B.J., S.D. Phillips, R.H. Wagner, R.P. Barth, D.J. Kolko, Y.M. Campbell, et al. 2004. "Mental Health Need and Access to Mental Health Services by Youths Involved with Child Welfare: A National Survey." Journal of the American Academy of Child \& Adolescent Psychiatry, Vol. 43, pp. 960-970.

Canadian Health Services Research Foundation. 2003. "The Integration of Health and Social Services for Young Children and their Families." Calgary, Alberta: Canadian Health Services Research Foundation.

Darlington, Y., J.A. Feeney \& K. Rixon. 2004. "Complexity, Conflict and Uncertainty: Issues in Collaboration between Child Protection and Mental Health Services." Children and Youth Services Review, Vol. 26, pp. 1175-1192.

Darlington, Y., Feeney, J.A. \& K. Rixon. 2005. Interagency Collaboration between Child Protection and Mental Health Services: Practices, Attitudes and Barriers." Child Abuse \& Neglect, Vol. 29, pp. 1085-1098.

Farmer, E.Z., B.J. Burns, M.V. Chapman, S.D. Phillips. \& E.J. Costello. 2001. "Use of Mental Health Services by Youth in Contact with Social Services." Social Service Review, Vol. 75, pp. 605-624.

Faver, C.A., Crawford, S.L., \& Combs-Orme, T. (1999). Services for child maltreatment: Challenges for research and practice. Children and Youth Services Review, 21, 89-109.

Flynn, R.J. \& B.A. Byrne. 2005. "Overview and Findings to Date of Research in the Ontario Looking After Children Project." Ontario Association of Children's Aid Societies Journal, Vol. 49, pp. 12-21.

Gable, S. 1998. School-Age and Adolescent Children's Perceptions of Family Functioning in Neglectful and Non-Neglectful Families.” Child Abuse \& Neglect, Vol. 22, pp. 859-867.

Hanrahan, N.P. \& D. Hartley. 2008. "Employment of Advanced-Practice Psychiatric Nurses to Stem Rural Mental Health Workforce Shortages.” Psychiatric $\quad$ Services, Vol. 59, pp. 109111. 
Kolko, D.J., B.L. Baumann \& N. Caldwell. 2003. "Child Abuse Victims' Involvement in Community Agency Treatment: Service Correlates, Short-Term Outcomes, and Relationship to Reabuse." Child Maltreatment, Vol. 8, pp. 273-287.

Kolko, D.J., Cohen, J.A., Mannarino, A.P., Baumann, B.L., \& Knudsen, K. (2008). Community treatment of child sexual abuse: A survey of practitioners in the national child traumatic stress network. Administration in Mental Health.

Lin, E., P. Goering, D.R. Offord, D. Campbell \& M.H. Boyle. 1996. The Use of Mental Health Services in Ontario: Epidemiologic Findings." Canadian Journal of Psychiatry, Vol. 41, pp. 572-577.

MacMillan, H.L. \& C. Munn. 2001. "The Sequelae of Child Maltreatment." Current Opinion in Psychiatry, Vol. 14, pp. 325-331.

McLennan, J.D., M. Caza, M. Boyle, R. McWilliam, D.R. Offord, K. Rondeau, et al. 2003. "The Integration of Health and Social Services for Young Children and their Families." Hamilton, Ontario: Offord Centre for Child Studies.

Paul, L.A., M.J. Gray, J.D. Elhai, P.M. Massad \& B.H. Stamm. 2006. "Promotion of EvidenceBased Practices for Child Traumatic Stress in Rural Populations." Trauma, Violence, \& Abuse, Vol. 7, pp. 260-273.

Ryan-Nicholls, K.D. \& J.M. Haggarty. 2007. "Collaborative Mental Health Care in Rural and Isolated Canada: Stakeholder Feedback." Journal of Psychosocial Nursing, Vol. 45, pp. 37-45.

Statistics Canada. 2004. "General Social Survey on Victimization (Catalogue no. 85-565XWE).” Ottawa, Ontario: Statistics Canada.

Statistics Canada. 2006. “2006 Census Catalogue (Catalogue no. 92-565-XWE).” Ottawa, Ontario: Statistics Canada.

Staudt, M.M. 2003. Mental Health Services Utilization by Maltreated Children: Research Findings and Recommendations." Child Maltreatment, Vol. 8, pp. 195-203.

Taussig, H.N. 2002. Risk Behaviors in Maltreated Youth Placed in Foster Care: A Longitudinal Study of Protective and Vulnerability Factors." Child Abuse \& Neglect, Vol. 26, pp. 11791199.

Tremblay, C., Hebert, M., \& Piche, C. (1999). Coping strategies and social support as mediators of consequences in child sexual abuse victims. Child Abuse \& Neglect, 23, 929-945.

Trocmé, N.M., B.J. MacLaurin, B.A. Fallon, J.F. Daciuk, D.A. Billingsley, M. Tourigny, et al. 2001. "Canadian Incidence Study of Reported Child Abuse and Neglect: Final Report." Ottawa, Ontario: Minister of Public Works and Government Services Canada, 2001. 
Trocmé, N., B. Fallon, B.J. MacLaurin, J.F. Daciuk, C. Felstiner, T. Black, et al. 2005. "Canadian Incidence Study of Reported Child Abuse and Neglect 2003: Major Findings." Ottawa, Ontario: Minister of Public Works and Government Services Canada.

Wekerle, C., E. Leung, A. Wall, R. Waechter, H. MacMillan, M. Boyle, et al. 2005. "AcademicAgency Research Partnerships in Practice: The MAP study." Ontario Association of Children's Aid Societies Journal, Vol. 49, pp. 26-34. 